NASA Technical Memorandum 81886

\title{
AIR CARGO MARKET OUTLOOK AND IMPACT \\ VIA THE NASA CLASS PROJECT
}

MatTHEW M. Winston AND

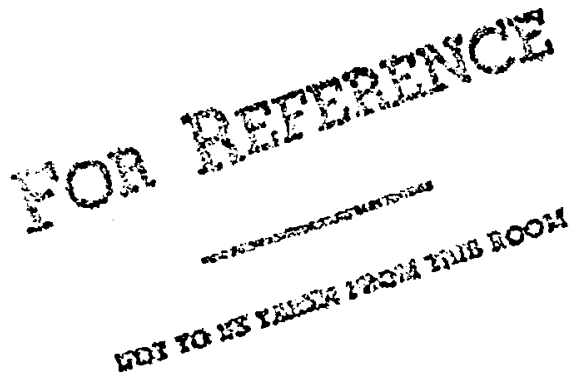

D. William Conner

OCTOBER 1980

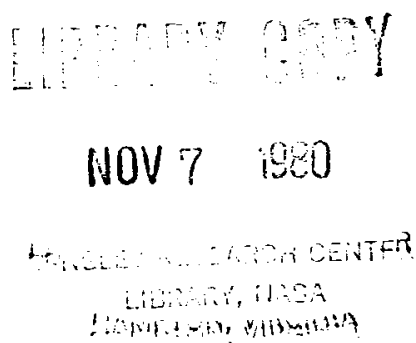





\title{
AIR CARGO MARKET OUTLOOK AND IMPACT VIA THE NASA CLASS PROJECT
}

\author{
By \\ Matthew M. Winston and D. William Conner \\ NASA Langley Research Center \\ Hampton, Virginia
}

SUMMARY

An overview is given of the Cargo/Logistics Airlift Systems Study (CLASS) project. CLASS was a 10 manyear effort carried out by two contractor teams, ained at defining factors impacting future system growth and obtaining market requirements and design guidelines for future airfreighters. Surveys of hundreds of major shippers, airframe manufacturers, airlines, freight forwarders, and government organizations afford a comprehensive view of the present system and its growth into the next century. Growth projection was estinated by two approaches: one, an optimal systems approach with a more efficient and costeffective system considered as being available in 1990; and the other, an evolutionary approach with an econometric behavior model used to predict long-term evolution from the present system. Both approaches predict significant growth in demand for international airfreighter services and less growth for U.S. domestic services. Economic analysis of airfreighter fleet options indicate very strong market appeal of derivative widebody transports in 1990 with little incentive to develop all-new dedicated airfreighters utilizing the 1990's technology until sometime beyond the year 2000. Advanced airfreighters would be economically attractive for a wide range of payload sizes (to 500 metric tons), however, if a government would share in the RD and $T$ costs by virtue of its need for a slightly modified version of a civil airfreighter design (e.g. military airlifter).

\section{INTRODUCTION}

The continuing growth of the air freight industry has become a subject of increased interest to NASA and other governinent agencies as well as to the airframe industry and those involved with cargo transport on a day-to-day basis. Although the growth to date is not the product of any concerted plan, it is now firmly believed that very careful consideration inust be given to the changes which are required to insure orderly future growth in the air cargo systeln. The Cargo/Logistics Airlift Systems Study (CLASS) project was formulated to: (a) define and analyze those factors which will impact future system growth; (b) obtain market requirements and design guidelines for future air cargo transports, and (c) identify the technology requirements essential to the develoment of a future dedicated airfreighter fleet.

The studies were initiated in inid-1977 and conducted over a two-year period under separate contracts by the Douglas Aircraft Company and the Lockheed-Georgia Company. The combined efforts of the contractors involved over 20,000 manhours, 
and the costs were about equally shared between them and NASA. Although both contractors addressed identical requirements as prescribed by NASA, they employed significantly different approaches so that their efforts were complementary rather than duplicatory. The final CLASS reports (refs. 1 and 2) contain more than 2500 pages of text and illustrative material, including a compendium of air cargo information gleaned from major shippers, airframe manufacturers, airlines, freight forwarders, and civil and military governinent organizations. The study results afford a comprehensive view of the present air cargo system and project its evolution into the next century. Previous reviews of CLASS which focused primarily on the market/aircraft demand analyses are given in references 3 and 4 . This paper is intended to give a brief review of the overall CLASS effort, to highlight a few of the major findings, and to comment upon the perspective derived therefrom. Since such a treatment risks oversimplification of many complex issues, the reader is referred to the formal CLASS reports for a more complete understanding of, and appreciation for, the overall project.

\section{STUDY OBJECTIVES AND METHODS}

The CLASS project was formulated at the Langley Research Center and monitored by a review team with representatives from a major shipper, the U.S. Department of Transportation, the USAF Military Airl ift Command, and NASA. The prime contractors, Lockheed-Georgia Company and Douglas Aircraft Company enlisted the aid of Trans-World Airlines and Flying Tiger Lines, respectively, as direct participants throughout the study effort. The primary study objectives were to:

(a) Evaluate and characterize present operations,

(b) contrast air cargo rates and service with surface modes,

(c) evaluate infrastructure and distribution system requirements,

(d) examine the role of advanced freighters in stimulating demand,

(e) assess institutional issues,

(f) analyze 1990 market potential for air cargo, and

(g) recommend NASA studies and research areas.

Toward satisfying these objectives, the contractors took significantly different approaches with regard to the major study elements receiving primary emphasis.

In the "optinal systen" approach taken by Lockheed (fig. 1), the emphasis was placed upon user response to a more efficient and cost effective advanced air cargo system. A 1990 scenario was developed in consultation with DOT and NASA. All of the attributes of the scenario are those which tend to improve service and promote air cargo systen growth. It included a projection of the cost and performance characteristics of all freight transport modes and supporting infrastructure together with a general description of the world economic condition in 1990. A large number of airfreight system users and carriers were then exposed to this scenario; and the results of their responses were combined with freight transportation statistics to derive the demand forecast and project the airfreighter fleet requirements.

The Douglas "evolutionary system" approach (fig. 2) placed heavy emphasis on an evaluation of the current air cargo systern. This evaluation was based upon 
extensive analyses of airport activity at sixteen cities representing both U.S. domestic and international airfreight operations. A statistical data base was then developed for the U.S. domestic and international markets as well as for 44 foreign carrier markets. These statistics, together with results from the current operations evaluation, were incorporated into an econometric behavioral mode1; and the results were used to predict the long-term evolution of airfreight markets. The predicted market behavior was combined with the results from a survey of airfreight system users and carriers to more fully identify the future system as it would evolve from the present until 1990. Included in that identification was the 1990 air cargo demand level from which the aircraft fleet requirements were determined. As discussed later, the results for 1990 obtained by this approach were subsequently used as a basis for analyzing air cargo fleet requirements out to the year 2008 .

\section{CLASS PROJECT FINDINGS}

The following discussion draws upon and condenses the major results of both studies. The discussion will address the various study elements in the following sequence: current operations analyses, surveys, 1990 scenario, demand forecasts, and 1990 airfreighter fleet requirements.

\section{Current Operations}

Market and route structures in both domestic and international operations (1976 data) were reviewed to determine cargo volumes, commodity flows, and capacity offered for major U.S. and international city pairs. Assessments were made of the factors which enter into selection of the air mode in order to determine the prinary selection criteria employed by users of the system. The system infrastructure was studied, including problems related to terminal operations and to airport access, operations, and growth constraints. The current operations analyses also included comparisons of the air delivery mode with other transport modes to contrast the volume, service, and cost characteristics of the air system with truck, rail, and ocean transport systems. The current use and impact of containers and other unit load devices were examined. Finally, the analyses focused upon institutional and economic issues such as curfews and the cost and availability of investment capital to show their impacts on air cargo system operations and growth potential.

The current air cargo system, while providing worldwide service, delivers only a very small fraction of the total freight tonnage (estimated to be about 0.1 percent). This is primarily because the systen has evolved as one which provides specialized service for small, high-value, perishable, time-sensitive, or emergency shipments; a market which is generally more service-sensitive than price-sensitive in terms of demand elasticity. The largest competitors for aireligible shipments are less-than-truckload (LTL) ground deliveries and ocean container lines. The entire air transport industry, passenger as well as freight, is capital intensive and very sensitive to fluctuations in the cost of equipment and 
investment capital. The airfreight industry, in addition, is particularly sensitive to cost increases in fuel, flight crew, and traffic servicing (e.g. landing fees).

The assessinents of terminal operations indicated wide variations among terminals in the levels of mechanization and computerization of cargo handling, poor cube utilization of containers, high personnel costs, and generally inefficient use of cargo processing space. Environmental issues have placed severe constraints on construction of new airports and on expansion at many existing airports where space for expanding cargo operations is rapidly disappearing. Since terminal costs are constant regardless of delivery distance, terminal operations are viewed as a potentially fruitful area for reducing operating costs.

of the several institutional issues which were addressed, one which caused major concern is the potential increase of curfews at airports around the world. It has been shown that the imposition of night-time curfews at a relatively few airports in the air cargo network could have far-reaching negative impacts on the air cargo industry and its customers (ref. 5). The U.S. domestic transport industry was undergoing deregulation during the course of the CLASS project. The studies therefore, gave only a cursory treatment to its potential effects on the current system while observing that, in time, deregulation will very likely have far-reaching effects.

\section{Surveys}

The surveys of airfreight system users and carriers were approached in a significantly different manner and were given a different focus in each study. However, the issues addressed and the character of the two groups of survey respondents were very similar. The major issues addressed in the surveys covered the same general subject areas as the "current operations analyses" and carried out by the contractors from the point of view of the detached observer. The survey results, in contrast, represent the points of view of the industry and its users. Since the survey participants included both providers and users of air cargo service, a broad range of viewpoints was obtained.

In the optinal systein study, eighty organizations representing U.S. and foreign shippers, consignees, carriers, and freight forwarders were given a description of the optimal 1990 air cargo system. From this description, they were faniliarized with the attributes of the postulated future scenario. The participants then provided written responses to detailed questionnaires related to the issues in view of the optimized scenario. Later, each respondent was interviewed to review his responses and to develop additional insights.

In the evolutionary system study, the survey participants were solicited for their responses to the issues against the background of the current system. They were also asked to indicate their desires for and potential demand response to enhanced system attributes for the future. Over 500 organizations provided written responses in this study; however, follow-up interviews were conducted with only 33 of those respondents. The extent of detail in the contractors' inquiries and the large number of responses provided significant insights into 
various aspects of the existing and future airfreight system--too many to cover here. The following selected results represent survey responses from both studies.

The inajor problems with the present air cargo system, in the respondents' views, were associated with ground support and handling rather than with the airport-to-airport segment. Included among the problem sources are such things as airport congestion, pickup, delivery, and customer service techniques. Most sinall shippers expressed limited interest in containers, since containers were viewed as benefiting primarily forwarders and large shippers. Paradoxically, these sinall shippers, as well as the large shippers, viewed intermodality as a vital element in any advanced air cargo system. Freight forwarders were generally viewed as being able to better fulfill shipper needs than airlines. The forwarders felt that their image of competing with airlines is counterproductive and advocated better communications and a more cooperative relationship with the airlines.

It was difficult to generalize from survey results with regard to modechoice decision criteria. High on the list was emergency use. Other considerations were transportation budgets, inventory control, and customer service in a conpetitive environment. The heavy users of airfreight placed greater emphas is on reduced damage, pilferage, and insurance. It was substantiated by the survey responses that, in general, the selection of the air mode for freight shipment is not rate-sensitive. A large number of commodities are more sensitive to service than to rates. The evolutionary study concluded from survey results that rate reductions up to 30 percent would not appreciably affect shipper demand for airfreight service. Both studies found that the concept of Total Distribution Cost (TDC) is not widely used by shippers and that transportation costs are generally viewed in isolation. The extent to which widespread use of the TDC concept would affect the modal-choice decision process was addressed, but no general consensus was obtained. With regard to the future air cargo system, the general consensus of responses to the surveys included primarily (a) a strong desire for intermodality, (b) an expression of the need for better airline/ forwarder relationships, and (c) an indication that rate reductions must exceed 30 percent in order to stimulate increased demand.

\section{The 1990 Scenario}

In the optimal system study, the air cargo systern scenario for 1990 was postulated to include only those attributes having a positive effect on increasing demand and system growth. Included were the following:

(a) The availability of cargo-optimized, advanced technology airfreighters and intermodal unit load devices,

(b) separation of cargo from passenger terminals,

(c) coordinated surface-air-surface operations,

(d) significant reductions in consolidation and break-bulk processing at the airport,

(e) rates for intermodal shipments based on door-to-door service,

(f) the accrual of significant rate reductions (45 percent) from reduced operating costs, and 
g) the absence of regulatory restraints which retard system development or use.

The evolutionary systern scenario for 1990 was projected from numerous current trends which included both growth inducements and contraints. Included anong the projected growth inducements, for example, was a significant increase in the percentage of cargo carried in shipper-loaded containers. By 1990, containers will be lighter and cheaper than those of today and will also be designed to facilitate higher levels of terminal mechanization and improved stacking efficiency. Another growth-inducing future development involves industry-wide use of computerized documentation and control. Typical of the factors which will serve to retard growth of the air cargo system are restrictions on construction of new airports and expansion of existing airports due to space linitations and enviromental issues; restrictions on aircraft size due to current airport regulations; and a proliferation of curfews, again due to increased environmental pressures. Significant also is the evolutionary system study conclusion that rate reductions of no more than about 24 percent can be expected by 1990 (in contrast to the 45 percent rate reduction postulated for the optinal system).

\section{Denland}

Each of the studies developed forecasts of future air cargo demand as a necessary step toward defining future fleet requirements. Denand projections for the optimal study were developed from traffic forecasts obtained from the U.S. Department of Transportation, the Air Transportation Association, the Organization for Economic Cooperation and Development, and the Maritime Administration (Fig. 3). These data were used to determine a future growth rate and combined with survey results (postulating 45 percent rate reduction) to determine the future penetration by the air mode of the total cargo traffic. For the domestic market, upper and lower boundaries of demand were obtained by assuming two different growth levels of passenger aircraft belly cargo load factor. Upper and lower boundaries for the free world international forecasts resulted froill a combination of assumptions among which were different growth rates and different levels of market penetration by the air mode.

The demand forecasts for the evolutionary study utilized a data base developed from current (1977) operations including traffic flows for the U.S. Domestic and international markets and 44 foreign carrier markets (Fig. 4). For each market seginent, a series of econonetric behavioral equations was developed to explain and forecast the evolutionary change of airfreight traffic from the 1977 base year operations. These equations incorporate factors to account for gross national products, inflation rates, exchange rate variations, and historical trends. Upper and lower boundaries of U.S. domestic dennand were established by utilizing two different estinates of the future trend of the price ratio of airfreight to motor freight. For the U.S. international and foreign markets, the boundaries were established by assuming two different estinates of the future trends in yield. The combined demand, was then adjusted downward to account for the fraction of cargo carried as belly freight. 
A summary of the demand forecasts for 1990 is given in figure 5. Actual demand data from 1977 are included for reference. Both studies predict significant growth in demand for international all-freighter service and somewhat less growth for domestic operations. The significant differences in the forecasts result primarily from the highly optimistic scenario postulated in the optimal system study. Another significant result is the prediction of a shift in the predominant airfreight routes from the North Atlantic to the North Pacific and to the trans-Asian routes (Europe to the Far East and Australia). Notable growth in the North America-to-South America traffic is indicated as well.

\section{Aircraft Selection}

From the foregoing demand analyses, the required types and numbers of allcargo aircraft for the 1990 time period were determined in each of the studies. The resulting airfreighter fleets are described in the following discussion.

Optimal System Study - The fleet analysis for the optimal system involved the integration of information gained from all of the CLASS study phases described previously. The relationships between air cargo volume and rates, candidate aircraft, operations costs, service frequency, and operator profitability were determined and modeled in a closed-loop computer analysis (fig. 6). The objective function of the model was maximization of operator earnings. Earnings as a function of deinand were then determined from 1977 air cargo rates and three levels of rate reduction $(15,30$, and 45 percent). The computer model also determined the optimum fleet mix for maximum earnings and hence defined the requireinents for aircraft in terms of numbers and payloads. A summary of the aircraft requirements analys is is given in Table 1.

The aircraft are characterized as being of conventional design but incorporating advanced technology. The primary difference in the aircraft required for domestic and international operations at a given payload is design range; $5520 \mathrm{~km}$ and $8800 \mathrm{~km}$, respectively. The table shows the numbers of aircraft required for both the high and low demand scenarios. The results indicate that by 1990 , coinbined U.S. domestic and international operations will require a total of about 112 to 278 aircraft of about 150 metric ton payload size and a smaller total number of 32 metric ton payload aircraft. The level of dernand for the international fleet will determine the predorninance of either large or small aircraft in the fleet mix. Continuing market growth beyond 1990 will result in diminished requirements for the sinaller aircraft and increased demand for the larger. Aircraft at 57 and 100 metric tons were also considered. The study concluded, however, that an insufficient demand would exist to encourage developinent of any dedicated freighter aircraft intermediate between the two sizes indicated.

Evolutionary System Study - The evolutionary study fleet analys is was based on the premise of evolutionary growth from 1977 to 1991. Separate analyses were conducted for three market segments -- U. S. domestic, U.S. international, and foreign. From these analyses, demand models and operational network model's were developed as functions of forecasted demand, aircraft capacity, and stage lengths for a large number of routes. This information, together with aircraft performance characteristics and investinent value, was used as input to a computer 
program. Various aircraft were tested in the model for each range element in the cargo market, with the aircraft providing the lowest trip cost for a given element being chosen. Summarizing the results of this operation provided a colnposite aircraft fleet in terms of numbers and types of aircraft.

Three different fleet options were evaluated. The first fleet consisted entirely of contemporary aircraft. The second was composed of near-terin and advanced derivatives of contemporary aircraft. The third fleet was a mix of near-term and advanced derivatives together with all-new, advanced-technology configurations. The numbers of various aircraft for the three fleet types were determined separately for the three market segments, and the phase in and phase out of aircraft as the market evolves over the 15-year study period was traced.

The fleet options are summarized in Tables 2, 3, and 4 and in figure 7 . Table 2 indicates that if contemporary transports are retained in service until 1900, the large narrow body aircraft (e.g. DC-8, B-707) and the widebody aircraft (e.g. DC-10, B-747) will comprise about 98 percent of the worldwide airfreighter fleet. If, on the other hand, contemporary aircraft are driven from the market by the superior economics of derivatives, the "all-derivative" fleet option given in Table 3 will evolve by 1990. About 84 percent of that fleet would be made up of 82-ton payload, near-term derivatives of current widebody transports. The results given in Table 4 indicate that even if a mixed airfreighter fleet including advanced concepts were to evolve by 1990, this 82-ton payload derivative would continue to serve the air cargo market in superior numbers. This result is particularly significant, since the advanced concepts include a large, all-new dedicated civil airfreighter. It appears from this analysis, therefore, that the very strong market appeal of derivative versions of current widebody transports will delay any incentive to develop an all-new airfreighter design to some time beyond the turn of the century.

\section{EVOLUTIONARY STUDY EXTENSION TO 1994-2008}

\section{Approach}

Following the studies previously discussed, the Douglas study was extended to determine the requirements for a family of dedicated airfreighters to the year 2008. In this study, the primary analytical tool employed was a computerized operational and economic simulation called Future Requirenents and Advanced Market Evaluation (FRAME). The essential features of the FRAME program are depicted schematically in figure 8. The progran accepts inputs developed from (a) the cargo system model (including network characteristics, market forecasts, system operational and economic constraints) and (b) the aircraft (technology, costs, performance). Its output data provide operational and economic information on the fleet mix of aircraft to satisfy the needs defined by the system model for time periods up to 15 years. The current study exercised the program for three 15-year periods with considerable overlap to insure continuity over the 30-year period of interest.

As stated earlier, the original evolutionary approach to developing the fleet mix of aircraft involved choosing the aircraft which provided for the 
lowest trip cost. In addition, the economic performance was initially based on a manufacturer "breaking even" at 200 units of production. It was recognized that in order to provide the manufacturer with an incentive to develop a new aircraft design, he must be allowed a reasonable rate of return (ROI) on his investinent. A value of 15 percent was chosen as a minimun ROI for the extended study and the "break even" approach was abandoned. Also, it was realized that, for those aircraft types in demand, there is a high probability that two manufacturers would participate in meeting that demand. The effects of one-versus-two manufacturers, therefore, were also examined.

The study logic was, in general, as follows: Historical data from the years 1967 to 1978 were outlined to assure continuity with the past and compatibility with the present systen. Then, 1978 fleet operations were extended to 1992 by the forecasting methods previously described, and an evaluation was made of current aircraft types in meeting the growing demand. This evaluation considered possible changes in the fleet mix in terms of numbers of aircraft of each of the various types and determined the effects of those changes in growth. Next, an assessinent was made of the potential for the entry of near-term derivatives into the fleet by 1985 followed by the entry of new (1990technology) dedicated freighters in 1995. Finally, the resulting fleet operational and economic characteristics were evaluated over the period 1994 to 2008. In addition, several study assumptions were varied to determine the impacts of (a) restricted growth in operational frequency, (b) reduced demand, (c) configuration options, and (d) military participation in partial absorption of the "front-end" development costs of all-new airfreighter designs. The following discussion will very briefly cover the significant aspects of the projected fleet operations and economics for the 1994-2008 time period and summarize the economic effects of configuration options and military participation.

\section{Results}

of the many interesting results derived from the study, a sample is illustrated in figure 9. The results are intended to show how well the all-new dedicated airfreighters would fare in competition with the reference fleet as described in Table 5. That is, given that the 1994-2008 reference fleet has evolved through the development of derivative aircraft together with the retention of a few current widebodies, the study determined the expected market for and potential economic performance of a new generation of airfreighters. The variations of fleet size, required airline fleet investment, and airline return on investinent are shown as functions of payload for dedicated 1990 technology airfreighters introduced in 1995. Included are the effects on economic performance of design range under the assumption that either a long range $(7022 \mathrm{~km})$ or a short range $(3218 \mathrm{~km})$ airfreighter will be developed, but not both. Also included are the economic effects of one-versus-two manufacturers. All costs are given in 1994 dollars.

The results show that there exists a maximum payload size which would be preferred; and surprisingly, that payload is relatively small. For advanced short range aircraft (ASR) the maximum preferred payload would be about 45 metric tons, a size at which the present worth of the airlines' fleet investment (\$108.6 
billion) would be a minimum and the return on investment would be a maximum (20.9 percent). For the advanced long range freighter (ALR), the results indicate that the preferred payload would be about 68 metric tons. At this size a larger market (more than 1250 aircraft) would exist, and a greater number of aircraft in the reference fleet would be replaced. If a single manufactuer were to produce all of the aircraft required, the airlines investinent would be reduced to about 93 billion dollars on which a return of about 25 percent would be realized. On the other hand, if two manufacturers participate in supplying aircraft to meet the inarket demand, the airlines' investment would increase substantially (up to about 111 billion dollars); and the airline ROI would decrease by nearly 3 percent. This result occurs primarily because with each manufacturer supplying only half the market, the aircraft unit acquisition price increases by about 12.5 million dollars per airplane. Consequently, the benefit of the advanced longrange airfreighter is marginal compared to the reference fleet when two manufacturers are involved.

The Mixed Payload Fleet - Although the initial economic analysis indicates the preferred airfreighter to be the advanced long range configuration supplied by a single manufacturer, there are other considerations which impact decisions which inight otherwise rest upon that result. As mentioned before, it is considered more probable that the demand would be met by at least two manufacturers. That eventuality alone degrades the economics to marginal status. It is also equally probable that a mix of short range (ASR) and long range (ALR) aircraft would provide the more satisfactory solution, given the realities of airline operations. In this case, one manufacturer would develop the short range aircraft and another would develop the long range aircraft. The projected market requirements indicate that this arrangement would result in the need for 623 of the ALR freighters and 949 of the ASR freighters. This fleet mix (ASR/ALR) would require an airline investment of about 106 billion dollars and earn an ROI of 23.3 percent. These numbers represent substantially improved economic attractiveness over both the dualmanufacturer, single-type ALR fleet and the reference fleet. This result, however, does not provide a recommended solution for the reasons given in the following discussion.

Effect of Departure Frequency Growth on Preferred Payload - The analysis indicated that the mixed fleet of long-range and short-range freighters consists of a total of 1572 airplanes. Such a large number of aircraft in the system by the year 2008 represents a growth in departure frequency of about 12.6 percent annually from 1978. This level of growth substantially exceeds the historical growth rate of 8.1 percent prior to 1978 and the forecasted 6.7 percent rate from which the reference fleet was derived. The impact on future airport flow control requirements could well be of unmanageable proportions. For this reason, the FRAME program was again exercised to examine the potential economic performance of an advanced airfreighter at a payload size which would result in the same $(6.7$ percent) departure frequency growth as that of the reference fleet. The resulting fleet consisted of 573 aircraft each having a payload of about 150 metric tons (called ALR-2). Again assuming the participation of two manufacturers, the economics were degraded, as expected, in comparison with the ASR/ALR fleet. On an 18 percent greater investment, the airlines would incur a 2.3 percent reduction in ROI. Moreover, the ALR-2 economics are less attractive than those of the reference fleet; and consequently, there would be little or no incentive for development of aircraft in this payload category. Table 6 contains 
a summary of the fleet economics derived from the foregoing analysis. The results given in Table 6 and the foregoing discussion again lead to the conclusion that derivative aircraft (reference fleet) will remain economically competitive for the next several decades. The study points out, however, that the degraded economics of a large all-new design (e.g. ALR-2) may not, in the final analysis, remove it from future consideration. It is conceivable that the combined effects of cargo market demand, airport and/or airways flow control, and perhaps even the energy situation could eventually force its development.

Government Participation - Because of the strong indication that normal market dynamics would not likely lead to aircraft of the ALR-2 (150 metric ton payload) size or larger, an analysis was conducted to determine the potential impact on airline economics of joint governinent/private industry development of a large airfreighter. The results of the analysis are shown in figure 10 . Subject to the conditions given at the top of the figure, the results show dramatic improvenents in airline economics. The 150 metric ton ALR-2 fleet investment is reduced by about 33 percent and the airline ROI is increased by about 6 percent as a result of governinent participation. Even more significant is the fact that aircraft in excess of 500 metric tons payload become economically competitive with the reference fleet by those measures of merit. It is most likely that the governinent's intended usage would involve military missions. No attempt was made, however, in this analysis to quantify the benefits of the foregoing arrangements to the military in obtaining reduced life cycle costs for their share of the aircraft. Nevertheless, it appears certain that cost-sharing of research, developinent, and tests and providing a market for increased production would result in some economic benefit to the military, as well as to the civil operator. The key remaining concern relates to the suitability of a comrnon aircraft design for performing both the civil and military missions. The U.S. Air Force has recently completed studies which specifically address this issue.

Outlook for Unconventional Airfreighter Designs - Because of the current interest in the apparent promise of some unconventional aircraft configurations, a brief study was conducted to provide a cursory examination of their economic potential. The assumptions were the same as the previous ones: (a) two manufacturers earning 15 percent return on investment (b) 1990 technology application and; (c) aircraft payload and number of units determined from demand forecasts. Included in the study were two propfan configrations $(0.7$ and 0.8 cruise Mach number) and a laminar flow control configuration, each at 150 metric ton payload. In addition, a 236 metric ton distributed load freighter (DLF) was analyzed. The aircraft characteristics were determined from previous NASA-and Air Forcesponsored design studies. Examples of the configurations are shown in figure 11.

The results shown in figures 12 and 13 indicate that, except for the large DLF, the fleet investinent is greater for all configurations than for the reference fleet, and that only the DLF and 0.7 Mach propfan provide a higher ROI. The much greater economic attractiveness of the 0.7 Mach propfan configuration as compared to the 0.8 Mach configuration is attributed to its higher structural efficiency and an assumed ten percent lower specific fuel consumption. Since a substantial improvernent in econonic performance is regarded as a necessary incentive to launch development of an all-new aircraft, only the 0.7 Mach propfan and the DLF show promise. There are other considerations, however, which tend to make these configurations less attractive than indicated. For example, the tech- 
nology required to provide operational gearboxes of the size needed for large propfan aircraft is not sufficiently well developed to insure its availability for application in the time period under consideration. Also, the study assumption that there would be no engine maintenance cost increment over that for turbofans may be optinistic. The large DLF will face operational constraints due to its size and incompatibility with present airport runways and other systems, and it is not easily adaptable to certain payload geometries and densities. Furthermore, because of its low aspect ratio, DLF fuel usage will be high; and operating costs could become prohibitive.

\section{PERSPECTIVE}

The CLASS project has provided a perspective of the air cargo systen -past, present, and future. Although no blueprint for the future energes, the historical aspects of the studies coupled with the realities of today provide a comprehensive background against which the future may be projected.

Because of the uncertainties in forecasting air cargo demand characteristics, the CLASS results should be applied with caution. For example, it is estimated that if the actual market growth lags the forecasted growth by five years going into 1994, the fleet composition and economic situation would be significantly impacted. In that likelihood, a very large percentage of current widebody aircraft will have been retained, and far fewer derivative aircraft will be in service. The market for an all-new large freighter would then shrink to a level where, if built at all, each airplane would cost about 50 million dollars more than the price originaily predicted. Obviously, the confidence of both operators and manufacturers in market predictions will become an increasingly important factor in future decision making.

On the other hand, the CLASS results point the airfreight industry in directions where near-term efforts can enhance the air cargo system with greater certainty. Improvements in terminal efficiency, better forwarder-airline relationships, positive steps toward achieving intermodality, and other efforts which reduce costs while improving service can be achieved by the industry. Recent initiatives by the U.S. Congress to obtain better understanding of the nature and problems of the airfreight industry may lead to positive results in tempering the impacts of institutional and regulatory constraints on industry growth.

CLASS analyses conclude that large distributed-load freighters, laminarflow-control aircraft, and other so-called "technology options" are not serious candidiates for airfreight service in the next several decades. The technology required to provide these options will continue to be pursued. However, their economic potential, in competition with derivatives of current widebody freighters will delay their initial application in the cargo market to some time well into the next century. Perhaps even more significant is the conclusion that the derivative aircraft will very likely diminish the economic incentive to develop any all-new conventional airfreighter as well. 
In contrast, CLASS results indicate that joint industry/government development of a common airfreighter design could lead to substantial economies. However, since the treatment given was cursory at best, a more extensive analysis is needed. The additional effort is particularly warranted since the U.S. Air Force is giving serious consideration to pursuit of such a joint venture in developing its next generation of large airlifters.

Because the CLASS project addressed a dynamic industry, its results are necessarily incomplete and dated. Its value, however, is not diminished on that account; for CLASS has brought cohesiveness to a wealth of scattered information and demonstrated in a credible fashion the merging of methodologies for technology and market forecasting. 


\section{REFERENCES}

1. J. M. Norman, R. D. Henderson, F. C. Macey and R. P. Tuttle: "Cargo/ Logistics Airlift Systems Study (CLASS)." Lockheed-Georgia Company, Marietta, Georgia, Volume I, NASA CR-158915; Volume II, NASA CR-158916 and Executive Sumnary, NASA CR-158959, 1978.

2. R. J. Burby and W. H. Kuhlman: "Cargo/ Logistics Airlift Systems Study (CLASS)." MCDonnell Dougl as Aircraft Company, Long Beach, Cal ifornia. Volume I, NASA CR-158912; Volume II, NASA CR-158913; Volume III, NASA CR-158914, 1978. Volume IV, NASA CR-158950, 1979.

3. Whitehead, Allen H., Jr.: "Characteristics of Future Air Cargo Demand and Impact on Aircraft Development (A Report on the Cargo/Logistic Airlift System Study (CLASS) Project). NASA TM 78774, 1978.

4. Whitehead, Allen H., Jr.; and Kuhlman, William H.: Demand for Large Freighter Aircraft as Projected by the NASA Cargo/Logistics Airlift systems Studies. NASA TM 80074, 1979.

5. N. K. Taneja, "The U.S. Airfreight Industry." D.C. Heath and Company, Lexington, Massachusetts, 1979. 
TABLE 1. - 1990 Dedicated Airfreighter Fleet (Optimal Systern Analysis)

\begin{tabular}{|c|r|r|r|r|}
\cline { 2 - 5 } \multicolumn{1}{c|}{} & \multicolumn{2}{c|}{ U.S. DOMESTIC FLEET } & \multicolumn{2}{c|}{ INTERNATIONAL FLEET } \\
\hline \multirow{3}{*}{ PAYLOAD } & \multicolumn{2}{|c|}{ DEMAND LEVEL } & \multicolumn{2}{c|}{ DEMAND LEVEL } \\
\cline { 2 - 5 } & LOW & HIGH & LOW & HIGH \\
\hline 32 METRIC TON & 34 & 34 & 105 & 45 \\
150 METRIC TON & 51 & 65 & 61 & 213 \\
& & & & \\
\hline
\end{tabular}

TABLE 2. - 1990 All-Freighter Fleet Option - Contemporary Aircraft (Evolutionary System Analysis)

\begin{tabular}{|c|c|c|c|c|c|}
\cline { 3 - 6 } \multicolumn{2}{c|}{$\begin{array}{c}\text { AIRCRAFT } \\
\text { TYPE }\end{array}$} & PAYLOAD, & \multicolumn{3}{|c|}{ NUMBER OF A S MARCRAFT UNITS } \\
\cline { 3 - 6 } & METRIC TONS & DOMESTIC & INT'L & MARKETS & \\
\hline SMALL NARROW BODY & 14 & - & - & 8 & 8 \\
WIDEBODY & 95 & 38 & 22 & 122 & 182 \\
\hline
\end{tabular}


TABLE 3. - 1990 All-Freighter Fleet Option - Derivative Aircraft (Evolutionary System Analysis)

\begin{tabular}{|c|c|c|c|c|c|}
\hline \multirow{3}{*}{$\begin{array}{c}\text { AIRCRAFT } \\
\text { TYPE }\end{array}$} & \multirow{3}{*}{$\begin{array}{l}\text { PAYLOAD, } \\
\text { METRIC TONS }\end{array}$} & \multicolumn{4}{|c|}{ NUMBER OF AIRCRAFT UNITS } \\
\hline & & \multicolumn{2}{|c|}{ U.S. MARKETS } & \multirow{2}{*}{$\begin{array}{l}\text { NON-U.S. } \\
\text { MARKETS }\end{array}$} & \multirow{2}{*}{ TOTALS } \\
\hline & & DOMESTIC & INT'L & & \\
\hline $\begin{array}{l}\text { SMALL NARROW BODY* } \\
\text { WIDEBODY* } \\
\text { WIDEBODY** }\end{array}$ & $\begin{array}{l}14 \\
82 \\
42\end{array}$ & $\begin{array}{r}2 \\
60 \\
38\end{array}$ & $\begin{array}{r}1 \\
33 \\
11\end{array}$ & $\begin{array}{r}7 \\
259 \\
7\end{array}$ & $\begin{array}{r}10 \\
352 \\
56\end{array}$ \\
\hline
\end{tabular}

* NEAR-TERM DERIVATIVE

** ADVANCED DERIVATIVE

TABLE 4. - 1990 All-Freighter Fleet Option - Derivative and AdvancedConcept Aircraft (Evolutionary System Analysis)

\begin{tabular}{|c|c|c|c|c|c|}
\hline \multirow{3}{*}{$\begin{array}{c}\text { AIRCRAFT } \\
\text { TYPE }\end{array}$} & \multirow{3}{*}{$\begin{array}{l}\text { PAYLOAD, } \\
\text { METRIC TONS }\end{array}$} & \multicolumn{4}{|c|}{ NUMBER OF A IRCRAFT UNITS } \\
\hline & & \multicolumn{2}{|c|}{ U.S. MARKETS } & \multirow{2}{*}{$\frac{\text { NON-U.S }}{\text { MARKETS }}$} & \multirow{2}{*}{ TOTALS } \\
\hline & & DOMESTIC & INT'L & & \\
\hline 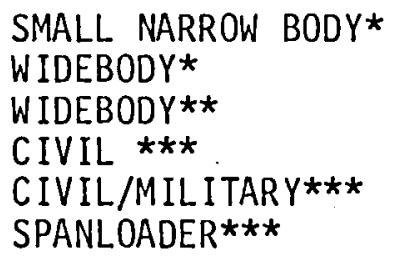 & $\begin{array}{r}14 \\
82 \\
42 \\
154 \\
59 \\
317,475\end{array}$ & $\begin{array}{l}- \\
13 \\
10 \\
14 \\
15 \\
10\end{array}$ & $\begin{array}{l}- \\
1 \\
1 \\
9 \\
- \\
8\end{array}$ & $\begin{array}{r}1 \\
107 \\
5 \overline{-} \\
\overline{19}\end{array}$ & $\begin{array}{r}1 \\
121 \\
11 \\
82 \\
15 \\
37\end{array}$ \\
\hline & $\begin{array}{ll}* & \text { NEAR } \\
\star * & \text { ADVAN } \\
\star \star * & \text { ADVAN }\end{array}$ & & & & \\
\hline
\end{tabular}


TABLE 5. - 1994-2008 Reference Airfreighter Fleet

\begin{tabular}{|l|c|c|}
\hline AIRCRAFT TYPE & PAYLOAD, & NUMBER OF UNITS \\
\hline METRIC TONS & & \\
CONTEMPORARY & 43 & 9 \\
LARGE NARROW BODY & 95 & 72 \\
WIDEBODY & & 437 \\
DERIVATIVE & 150 & 379 \\
\hline SHORT RANGE & 150 & \\
LONG RANGE & & \\
\hline
\end{tabular}

TABLE 6. - Evolutionary Fleet Economic Summary 1994-2008

\begin{tabular}{|l|r|r|r|c|c|c|}
\cline { 2 - 7 } \multicolumn{1}{c|}{} & \multicolumn{1}{c|}{ ASR } & ALR & \multicolumn{1}{c|}{ ALR } & ASR/ALR & ALR-2 & REFERENCE \\
\hline NO. OF MANUFACTURERS & 1 & 1 & 2 & 2 & 2 & \\
DESIGN RANGE, km & 3218 & 7022 & 7022 & $3218 / 7022$ & 7022 & 3218 T0 7022 \\
PAYLOAD, METRIC TON & 45 & 68 & 68 & $45 / 68$ & 150 & 43 to 150 \\
NUMBER OF AIRCRAFT & 980 & 1253 & 1253 & $949 / 623$ & 573 & 897 \\
A IRLINE INVESTMENT & & & & & \\
\$B ILLION (1994) & 108.6 & 93.4 & 110.7 & 105.7 & 124.2 & 113.5 \\
ROI, PERCENT & 20.9 & 25.1 & 22.3 & 23.3 & 21 & 21.4 \\
\hline
\end{tabular}





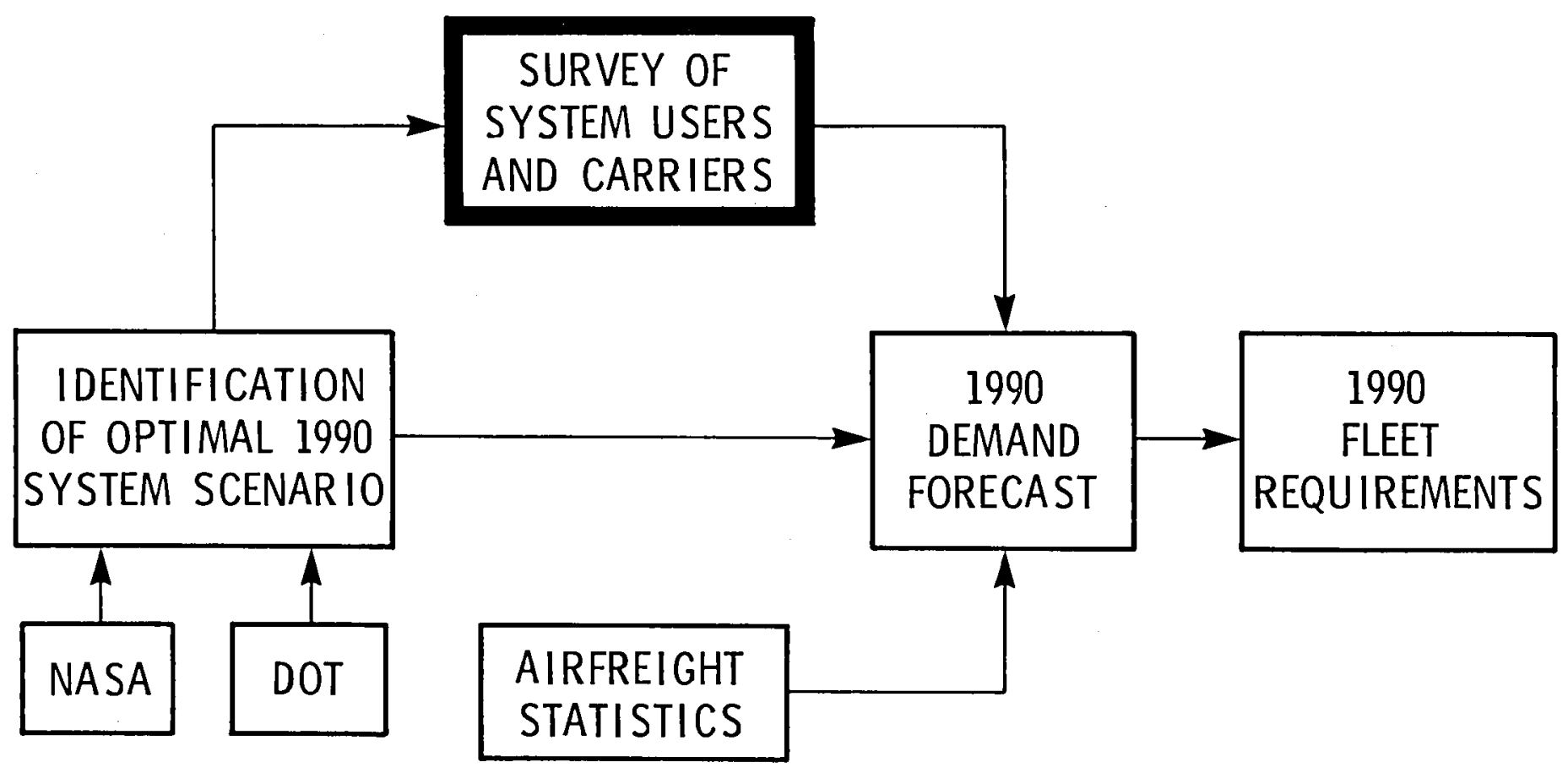

Figure 1.- Lockheed "optimal system" approach. 


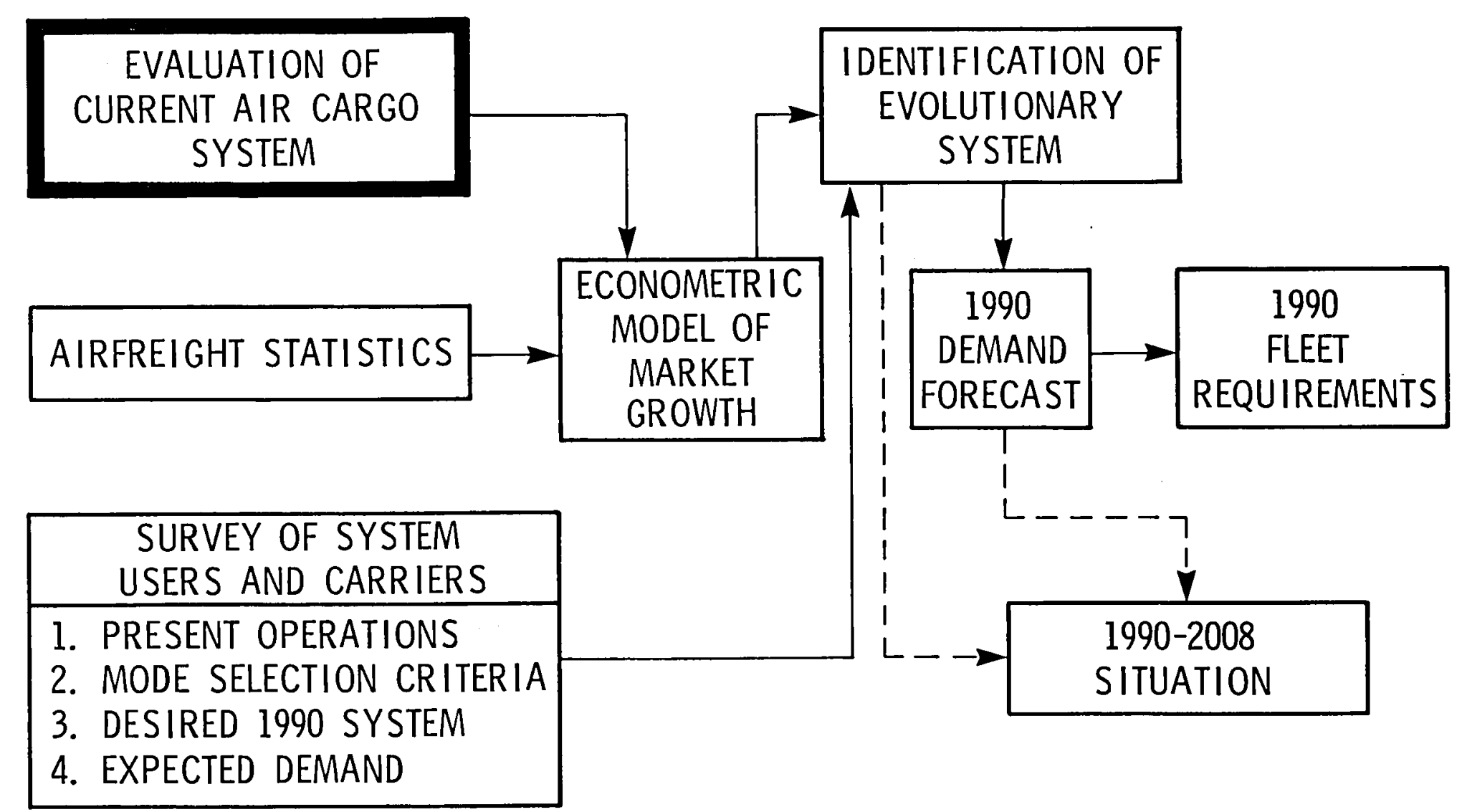

Figure 2.- Douglas "evolutionary system" approach. 


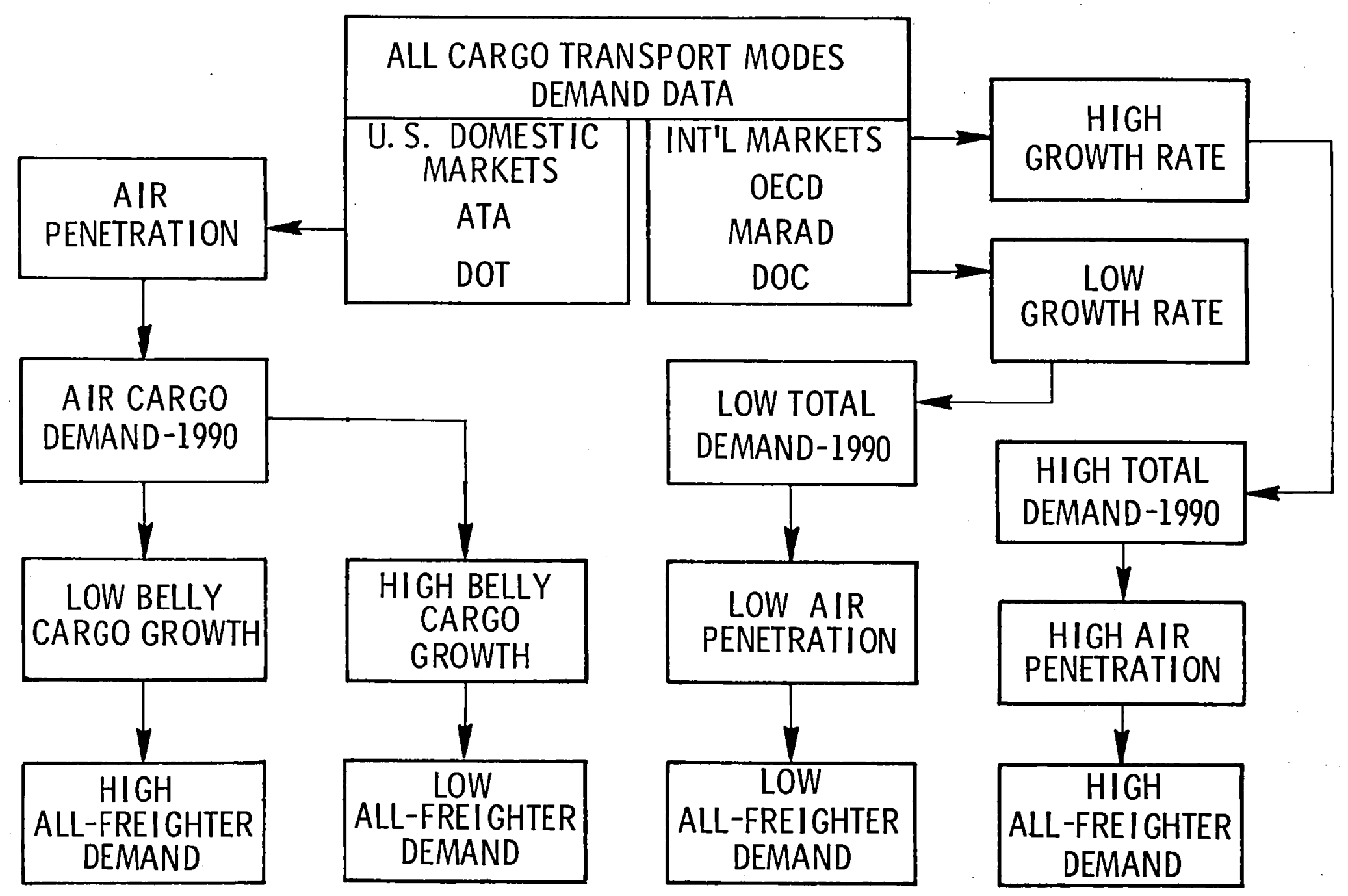

Figure 3.- 1990 all-freighter demand forecast - "optimal system" study. 


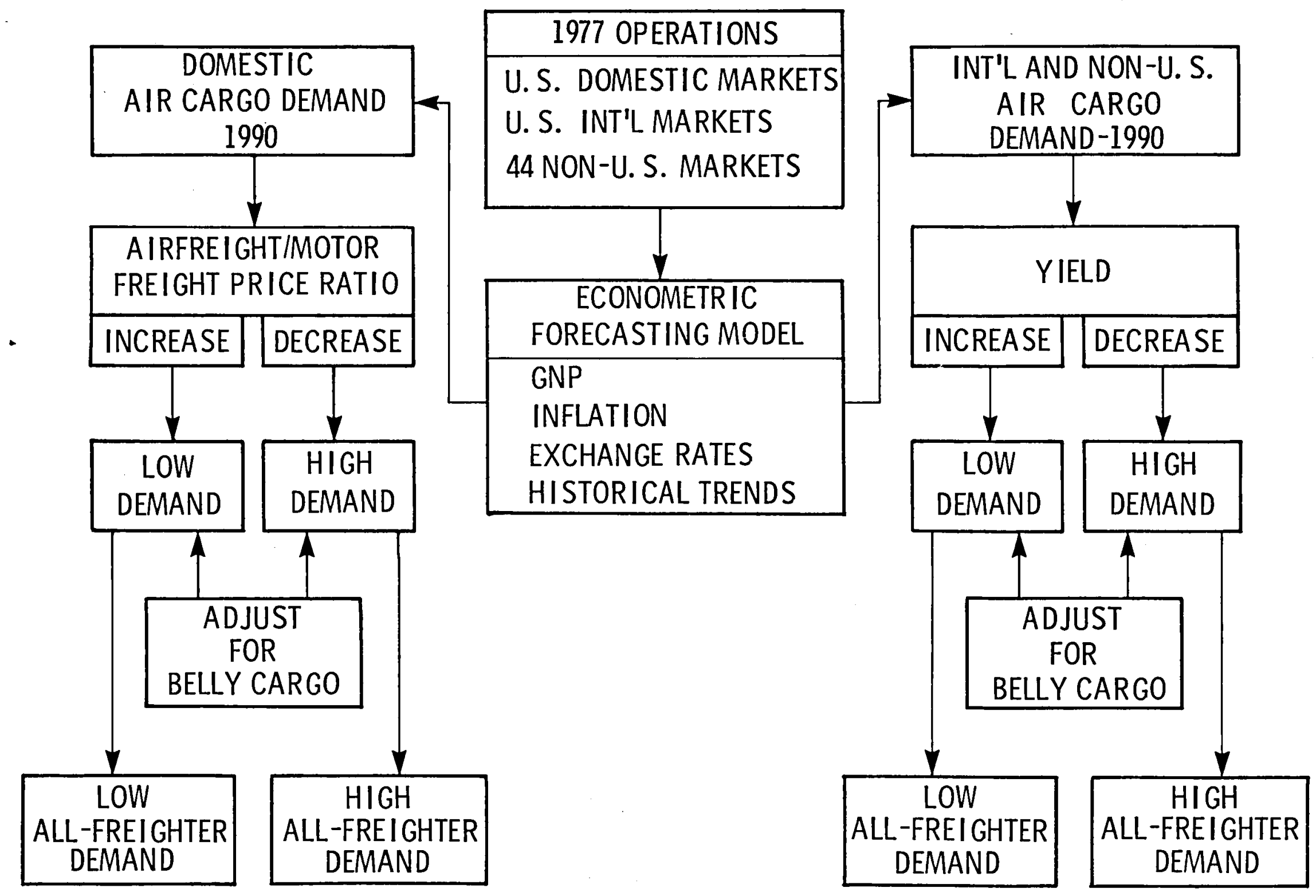

Figure 4.- 1990 all-freighter demand forecast - "evolutionary system" study. 


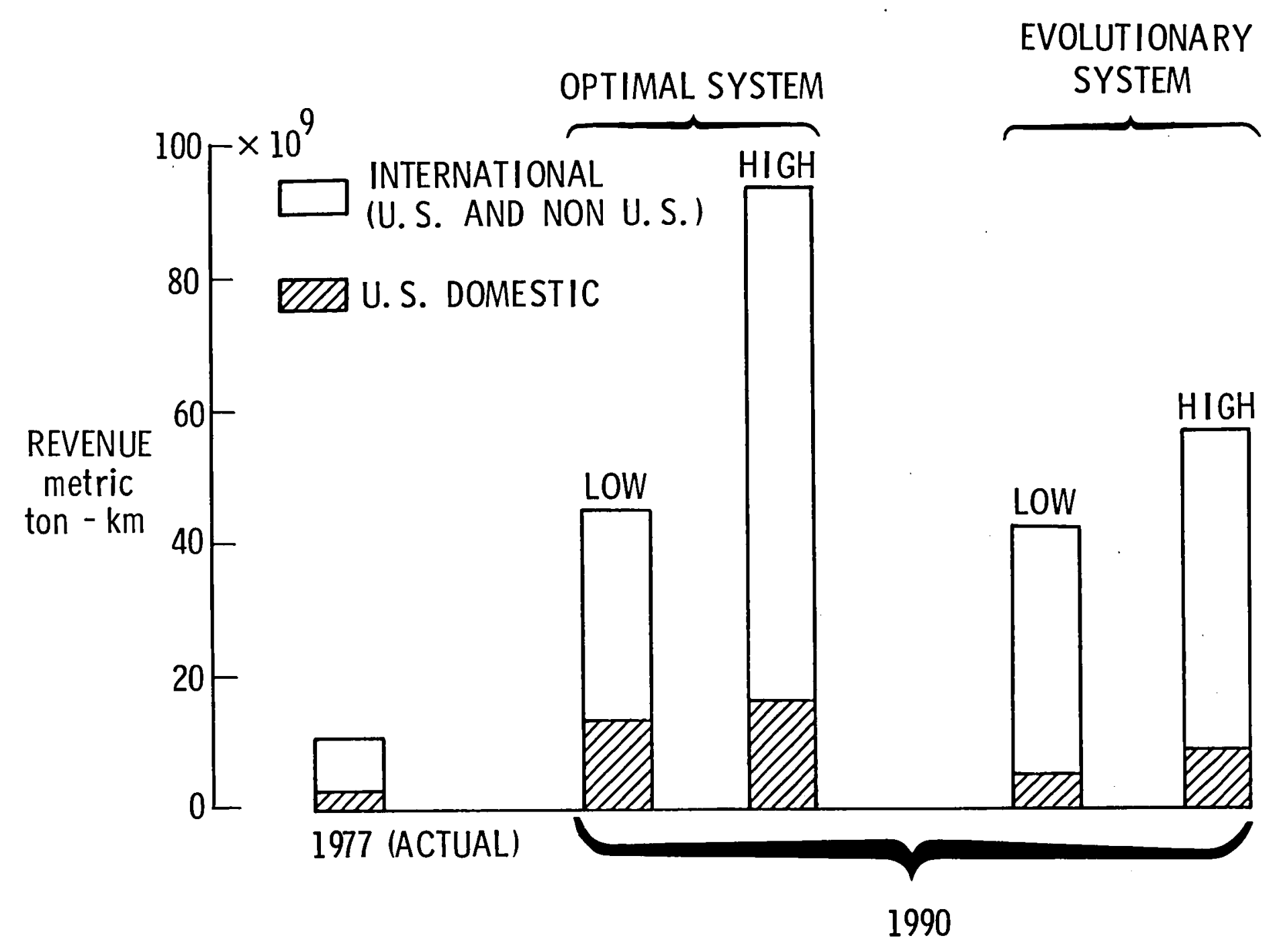

Figure 5.- Summary of 1990 all-freighter demand forecasts. 


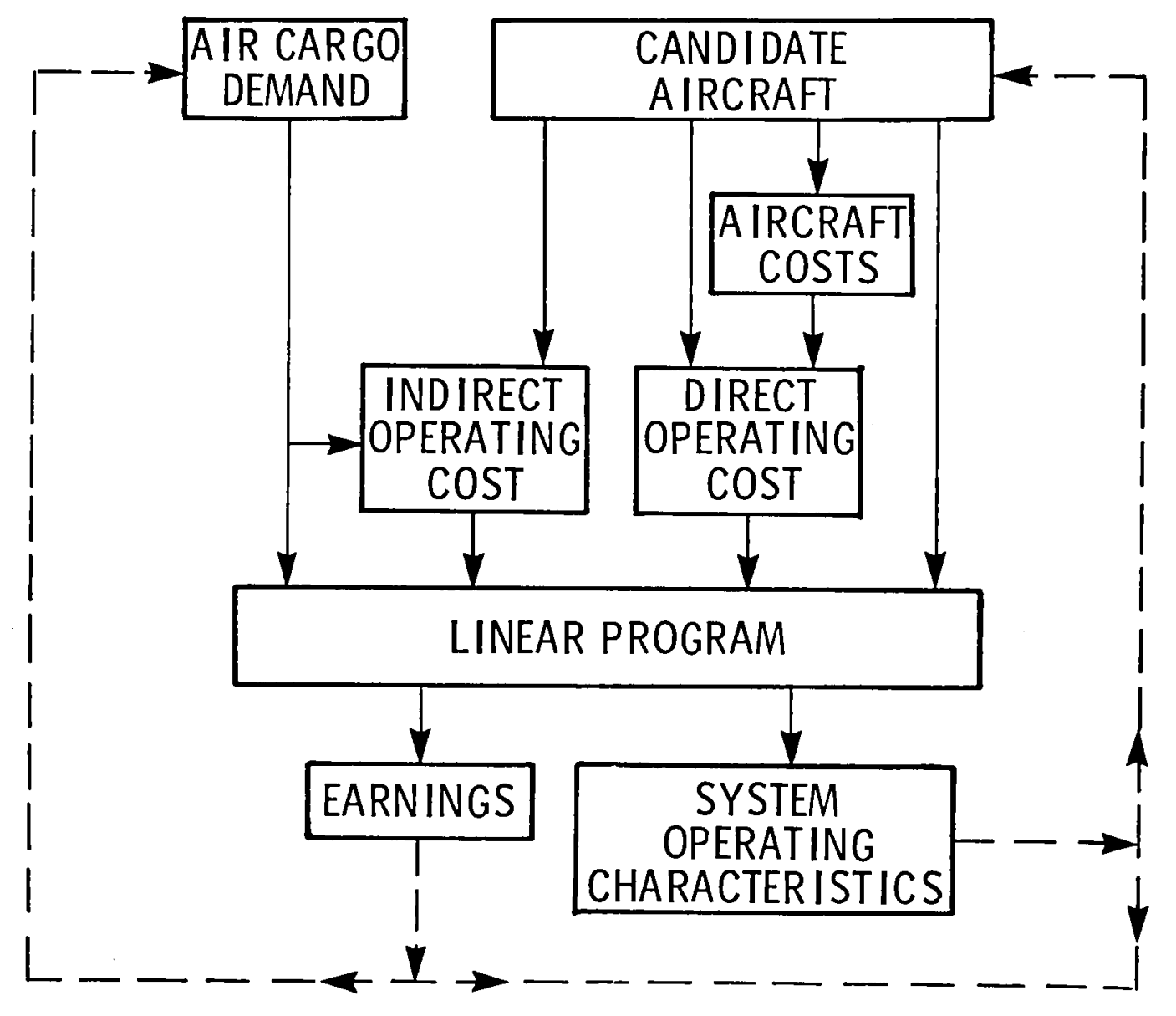

Figure 6.- Fleet analysis program - "optimal system" study. 


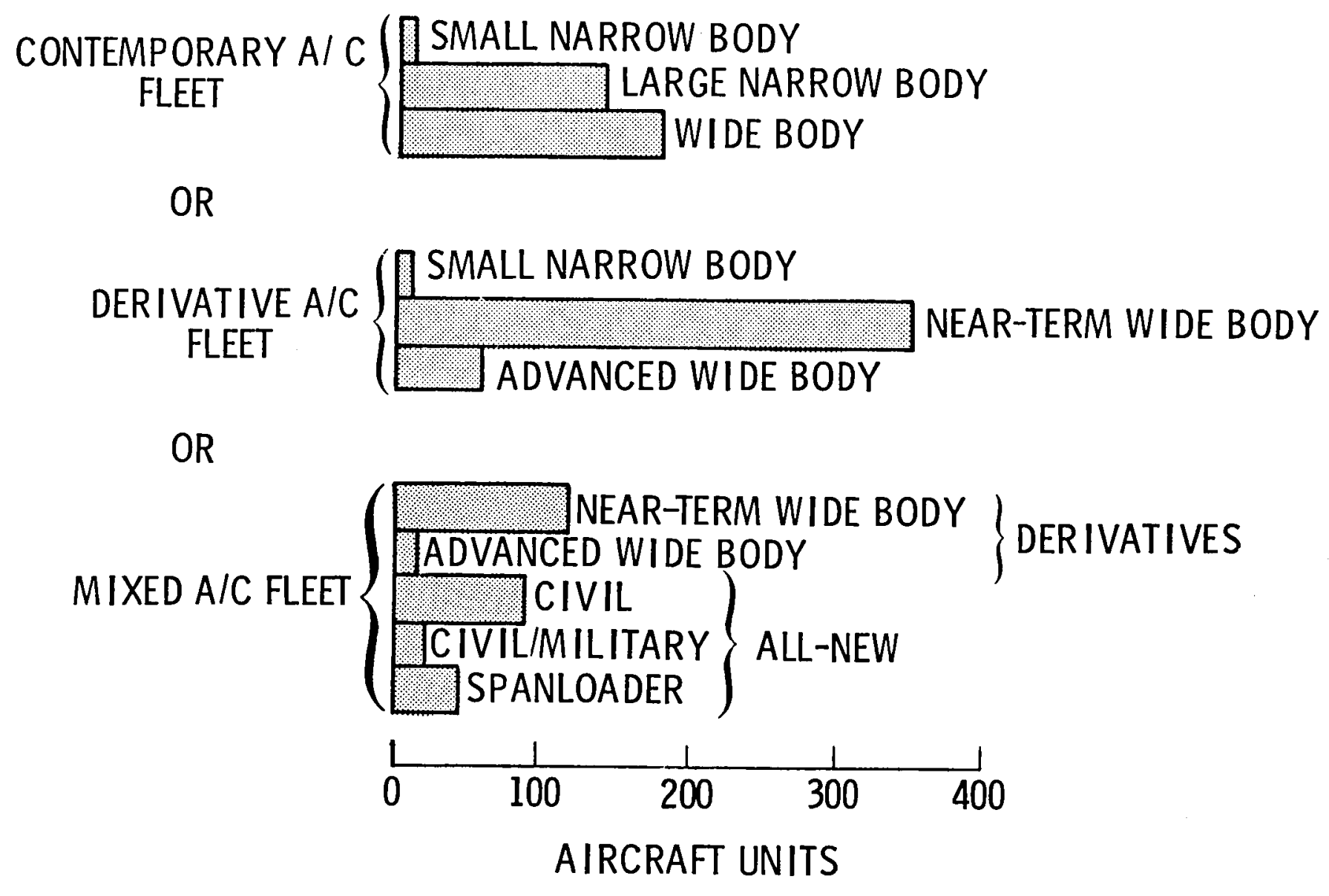

Figure 7.- 1990 al1-freighter fleet options - "evolutionary system" study. 


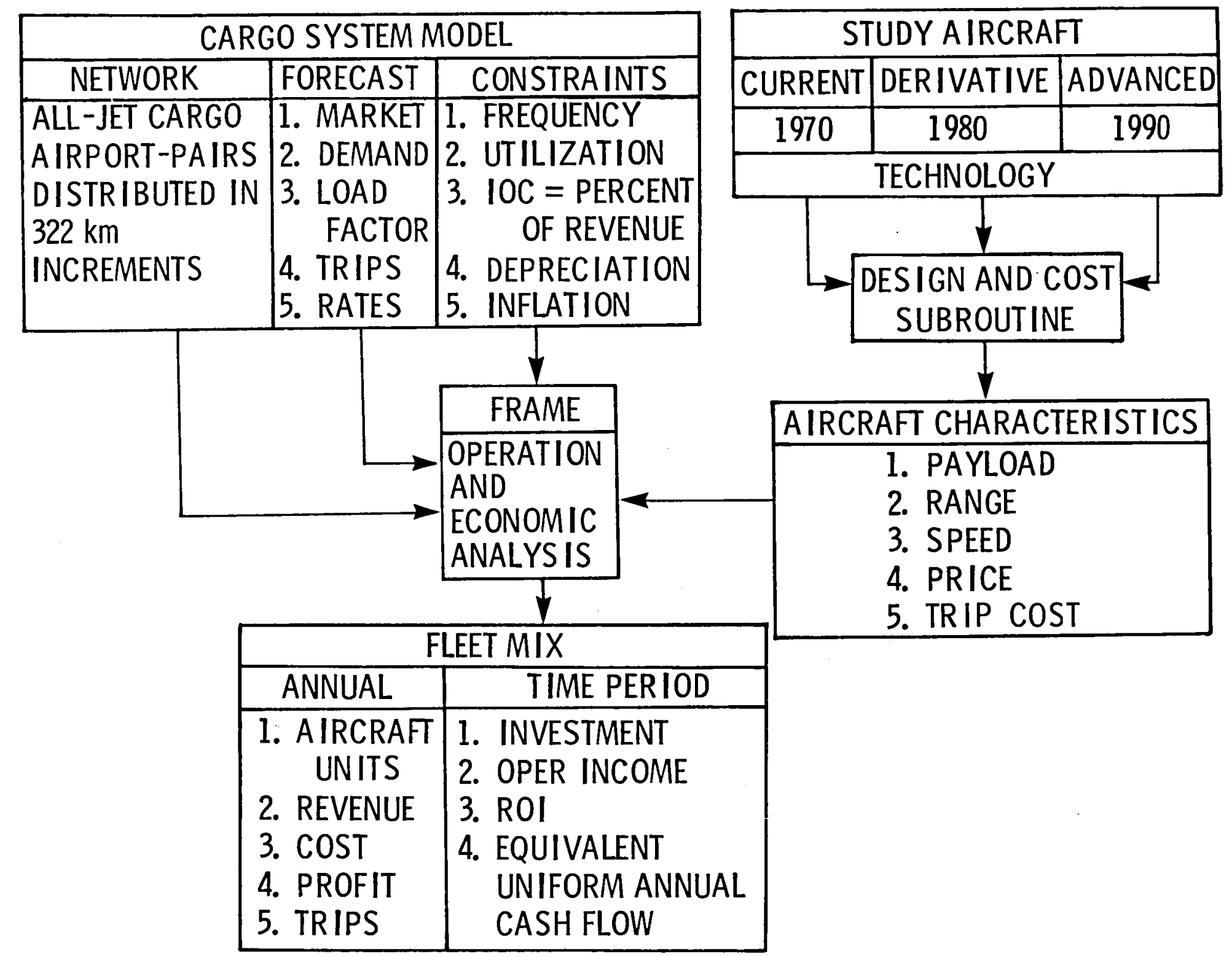

Figure 8. - Methodology for 1994-2008 aircraft requirements study - FRAME. 


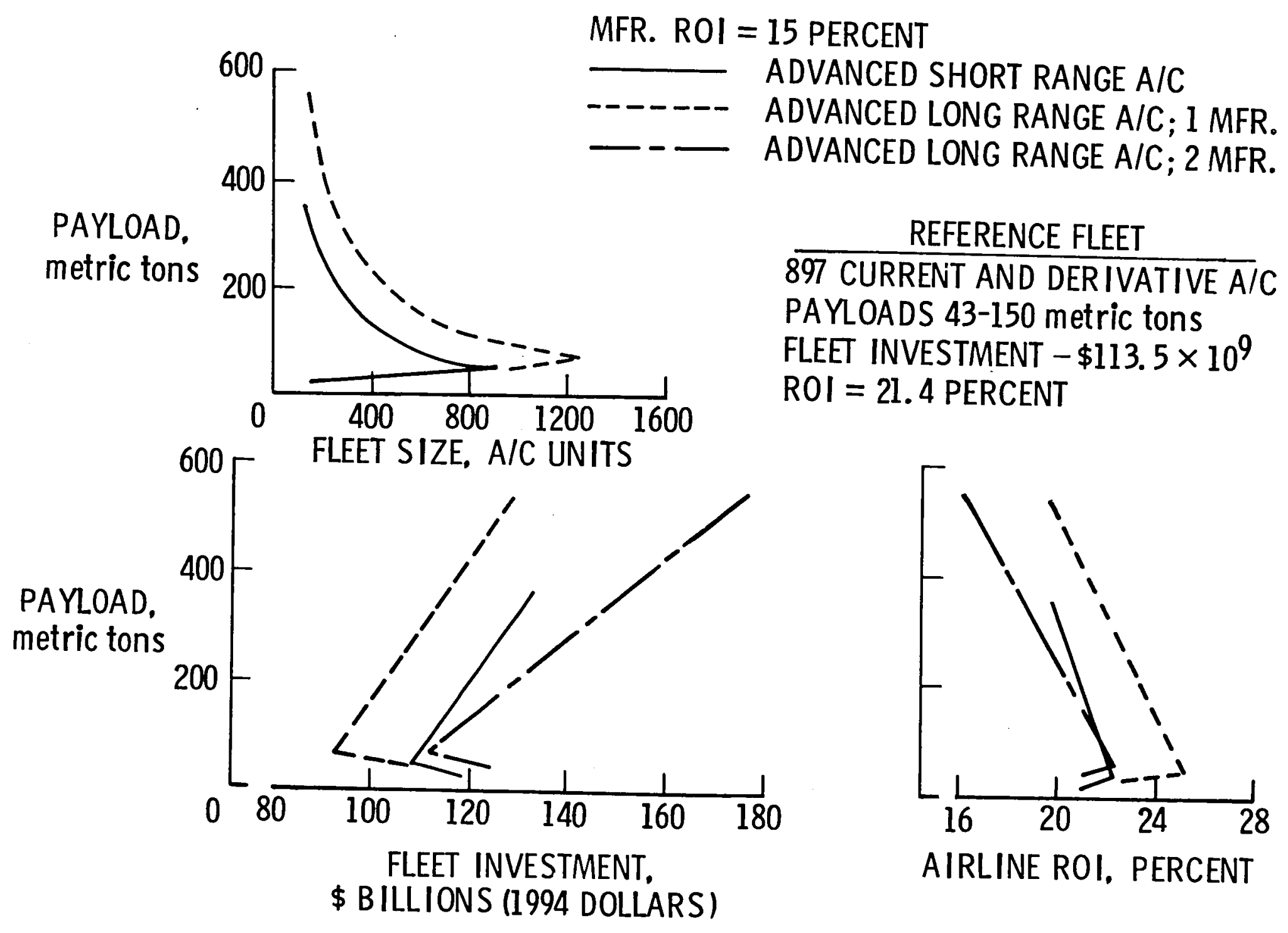

Figure 9.- Economics of 1994-2008 fleet options. 


\section{ASSUMPTIONS \\ - MARKET FROM 1994 TO 2008 SPLIT BETWEEN TWO MANUFACTURERS \\ - GOVERNMENT FUNDS 50 PERCENT OF R, D, AND T FOR ONE MANUFACTURER \\ - GOVERNMENT BUYS EQUAL 25 PERCENT OF U.S. CARRIER BUYS \\ - GOVERNMENT REQUIREMENTS IMPOSE NO PENALTIES ON AIRCRAFT \\ - MANUFACTURERS RETURN ON INVESTMENT - 15 PERCENT}

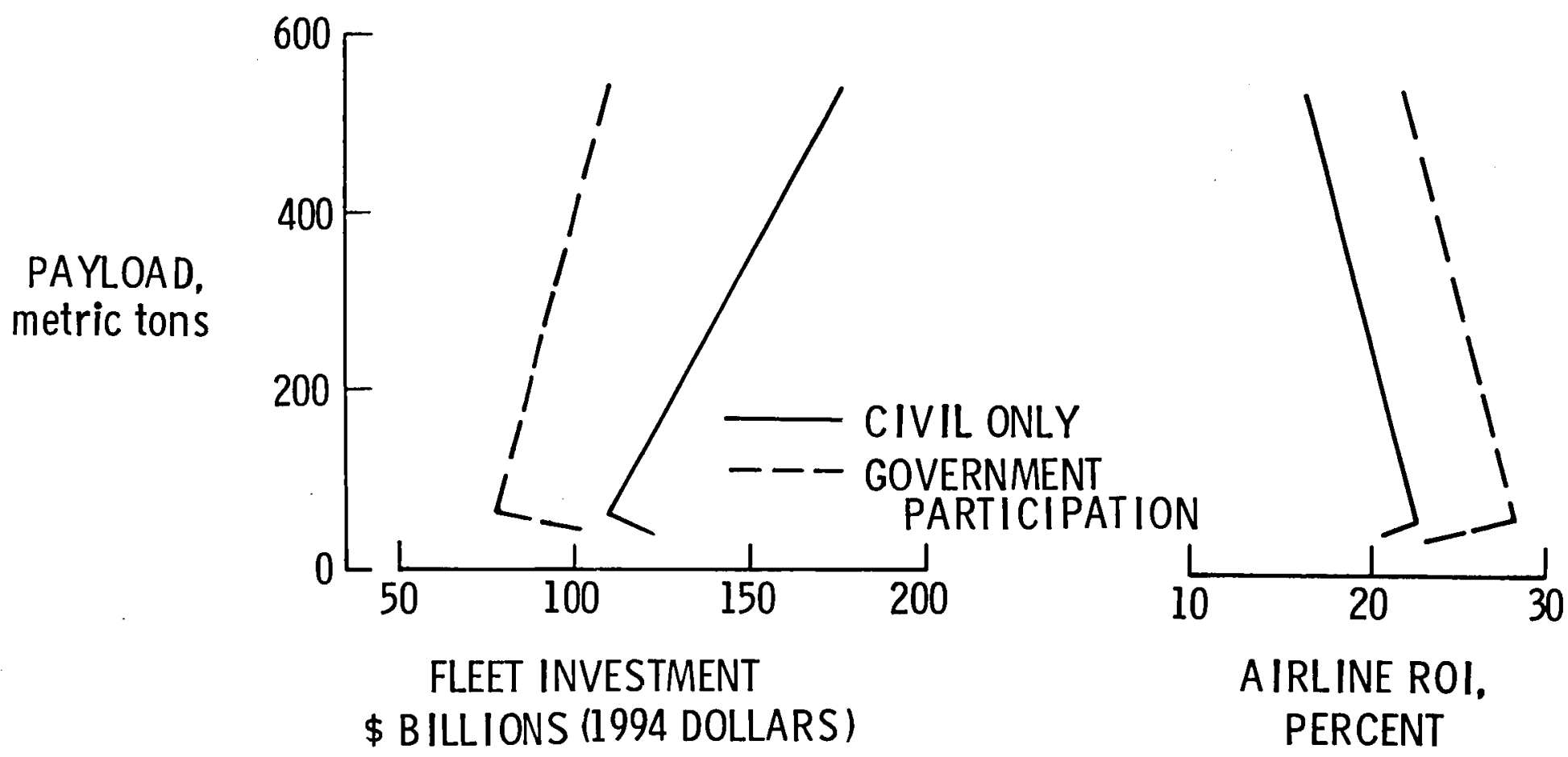

Figure 10.- Economic impact of government participation. 


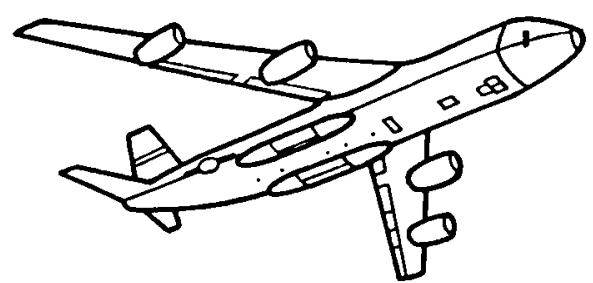

NEW TURBOFAN (CONVENTIONAL)

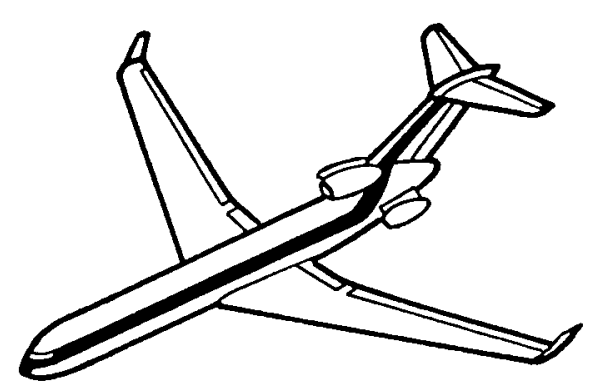

LAMINAR FLOW CONTROL

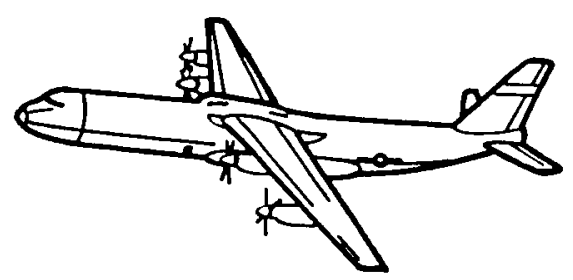

PROPFAN

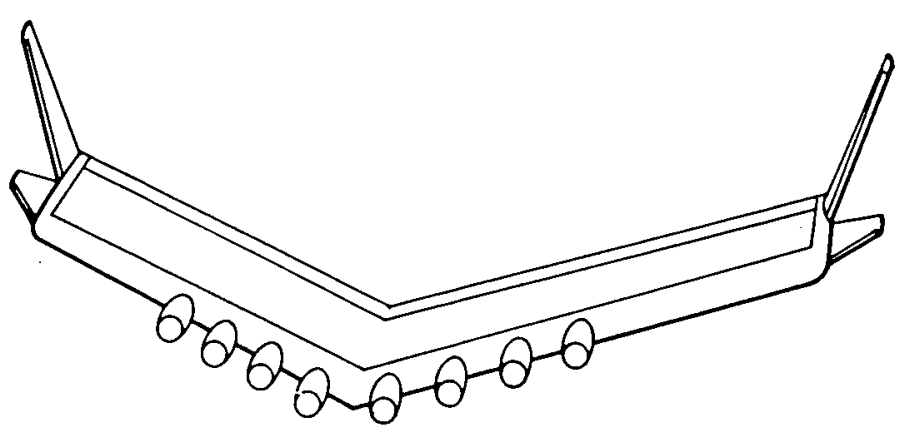

DISTR IBUTED LOAD

Figure 11.- Technology options for future airfreighters. 

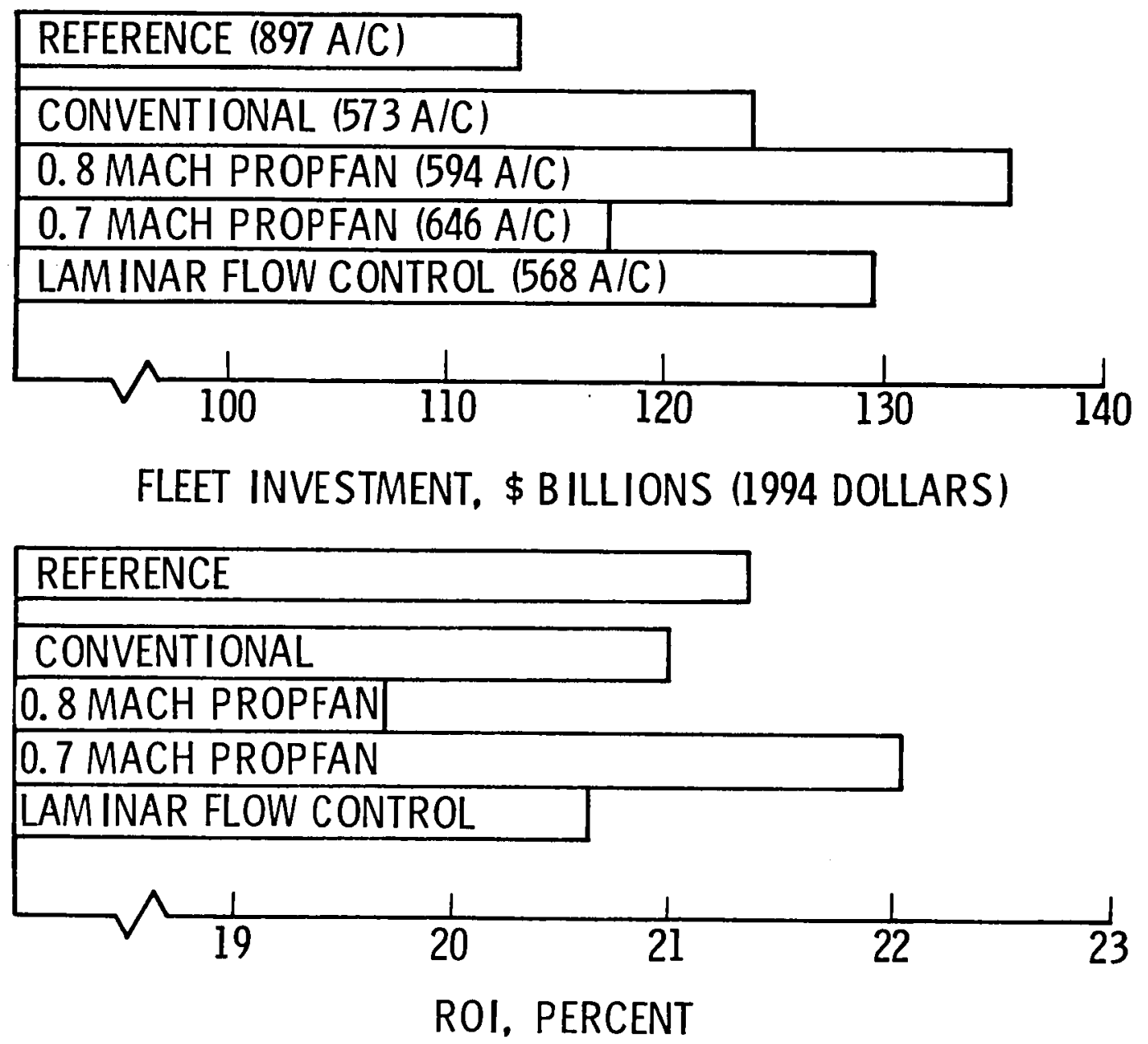

Figure 12.- Economic outlook for 150-metric ton technology options. 

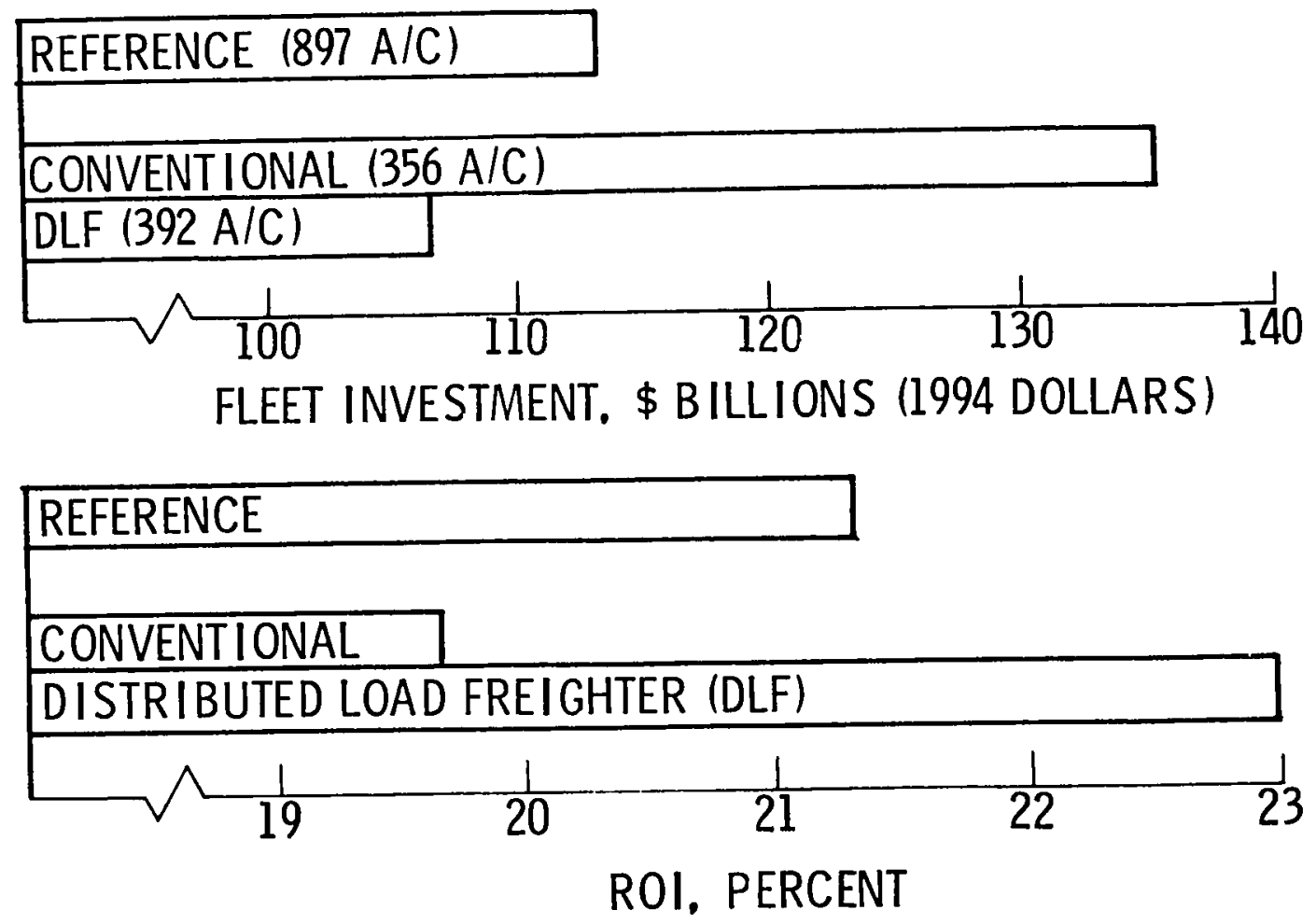

Figure 13.- Economic outlook for 236-metric ton technology options. 


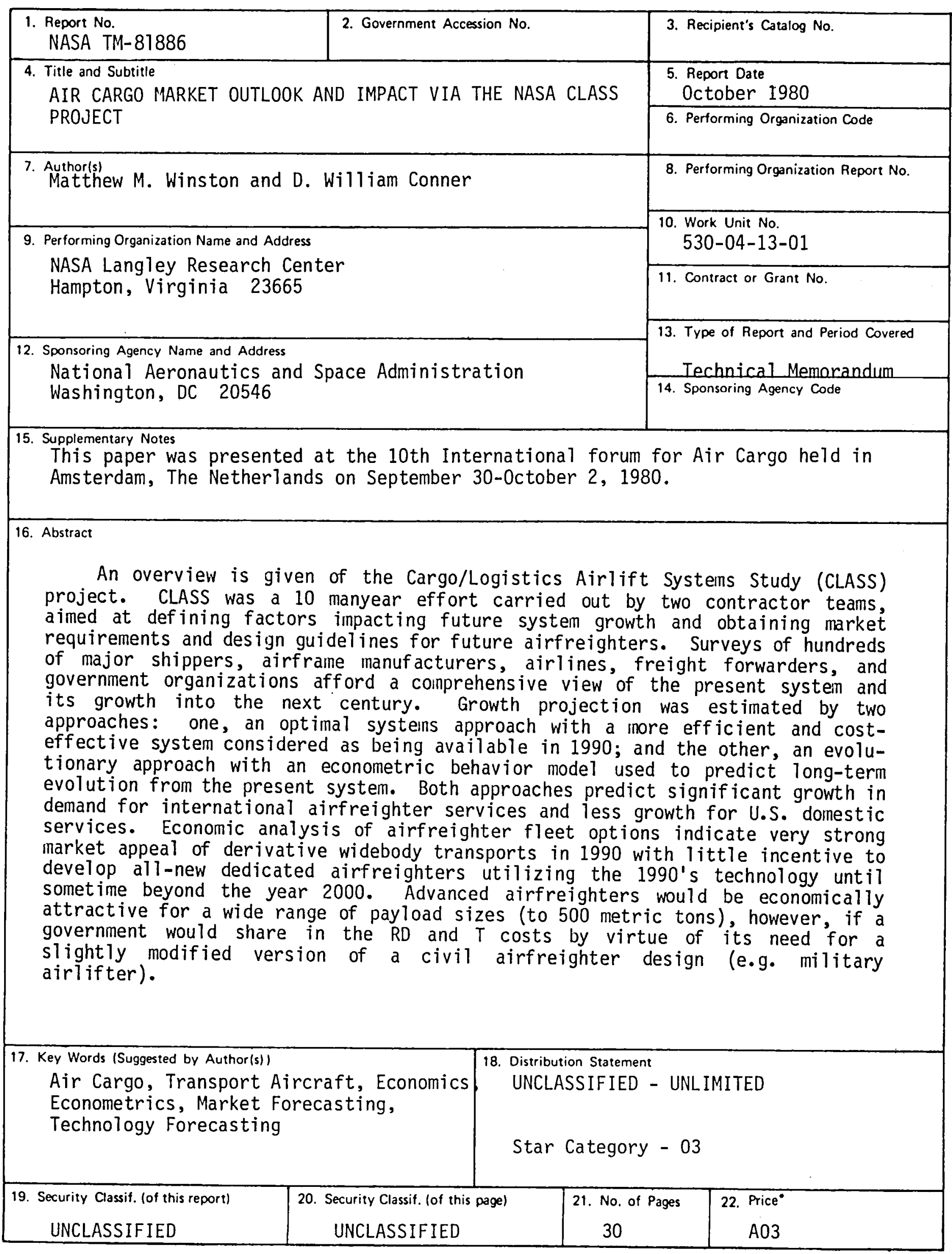




\author{
.
}



